\title{
Carrot Consumption Frequency Associated with Reduced BMI and Obesity through the SNP Intermediary rs 4445711
}

\author{
Kazuya Fujihara ${ }^{1}$, Shun Nogawa ${ }^{2}$,, Kenji Saito ${ }^{2}$, Chika Horikawa ${ }^{3}{ }^{D}$, Yasunaga Takeda ${ }^{1}$, Kaori Cho ${ }^{1}$, \\ Hajime Ishiguro ${ }^{1}$, Satoru Kodama ${ }^{1}$, Yoshimi Nakagawa ${ }^{4}$ (D), Takashi Matsuzaka ${ }^{5}$, Hitoshi Shimano ${ }^{5}$ \\ and Hirohito Sone ${ }^{1, *(1)}$
}

\section{check for}

updates

Citation: Fujihara, K.; Nogawa, S. Saito, K.; Horikawa, C.; Takeda, Y.; Cho, K.; Ishiguro, H.; Kodama, S.; Nakagawa, Y.; Matsuzaka, T.; et al. Carrot Consumption Frequency Associated with Reduced BMI and Obesity through the SNP Intermediary rs4445711. Nutrients 2021, 13, 3478. https://doi.org/ $10.3390 /$ nu13103478

Academic Editor: Joerg Koenigstorfer

Received: 19 August 2021

Accepted: 28 September 2021

Published: 30 September 2021

Publisher's Note: MDPI stays neutral with regard to jurisdictional claims in published maps and institutional affiliations.

Copyright: (C) 2021 by the authors Licensee MDPI, Basel, Switzerland. This article is an open access article distributed under the terms and conditions of the Creative Commons Attribution (CC BY) license (https:/ / creativecommons.org/licenses/by/ $4.0 /)$.
1 Department of Internal Medicine, Niigata University Faculty of Medicine, Niigata 951-8510, Japan; kafujihara-dm@umin.ac.jp (K.F.); mr2.yac@gmail.com (Y.T.); yokokawa0323@gmail.com (K.C.); power@med.niigata-u.ac.jp (H.I.); ybbkodama@gmail.com (S.K.)

2 Genequest Inc., Tokyo 108-0014, Japan; nogawa@genequest.jp (S.N.); sk@genequest.jp (K.S.)

3 Department of Health and Nutrition, Faculty of Human Life Studies, University of Niigata Prefecture, Niigata 950-8680, Japan; horikawa@unii.ac.jp

4 Department of Research and Development, University of Toyama Institute of Natural Medicine, Tomaya 930-8555, Japan; ynaka@inm.u-toyama.ac.jp

5 Department of Internal Medicine, University of Tsukuba School of Medicine, Tsukuba 305-8577, Japan; t-matsuz@md.tsukuba.ac.jp (T.M.); hshimano@md.tsukuba.ac.jp (H.S.)

* Correspondence: sone@med.niigata-u.ac.jp; Tel.: +81-25-368-9026

\begin{abstract}
It is unclear whether genetic interactions are involved in the association between vegetable intake and reduced body mass index (BMI) or obesity. We conducted a comprehensive search for single nucleotide polymorphisms (SNPs) which are associated with the interaction between vegetable intake frequency and BMI or obesity. We performed a genome-wide association analysis to evaluate the genetic interactions between self-reported intake of vegetables such as carrot, broccoli, spinach, other green vegetables (green pepper and green beans), pumpkin, and cabbage with BMI and obesity, which is defined as a BMI $\geq 25.0 \mathrm{~kg} / \mathrm{m}^{2}$ in the Japanese population $(n=12,225)$. The mean BMI and prevalence of obesity was $23.9 \pm 3.4 \mathrm{~kg} / \mathrm{m}^{2}$ and $32.3 \%$ in men and $22.1 \pm 3.8 \mathrm{~kg} / \mathrm{m}^{2}$ and $17.3 \%$ in in women, respectively. A significant interaction was observed between rs 4445711 and frequency of carrot intake on BMI $\left(p=4.5 \times 10^{-8}\right)$. This interaction was slightly attenuated after adjustment for age, sex, alcohol intake, smoking, physical activity and the frequency of total vegetable intake $\left(p=2.1 \times 10^{-7}\right)$. A significant interaction was also observed between rs4445711 and frequency of carrot intake on obesity $\left(p=2.5 \times 10^{-8}\right)$. No significant interactions that were the same as the interaction between frequency of carrot intake and rs4445711 were observed between the intake frequency of broccoli, spinach, other green vegetables, pumpkin or cabbage and BMI or obesity. The frequency of carrot consumption is implicated in reducing BMI by the intermediary of rs4445711. This novel genetic association may provide new clues to clarify the association between vegetable intake and BMI or obesity.
\end{abstract}

Keywords: carrot intake; body mass index; single nucleotide polymorphism; rs4445711

\section{Introduction}

Vegetables are an important part of a healthy eating pattern and provide sources of many nutrients. Vegetable intake may be a key modifiable factor in the prevention of chronic diseases such as diabetes, hypertension, and cardiovascular disease [1,2]. Being overweight or obese represents a major public health problem worldwide [3-5]. Obesity is an important contributing factor to the global incidence of diabetes, cardiovascular disease, and cancer, leading to a reduced quality of life [6,7]. So far, there has been no consistent finding on the association between vegetable consumption and body mass index (BMI) or obesity [8-15]. While several studies have shown that the intake of some vegetables 
is negatively associated with BMI [9-13,16], some studies have reported that there was no association between vegetable intake and a subsequent decrease in BMI $[12,14,15]$. Genetic factors have been reported to be associated with the consumption of vegetables. Matoba et al. showed that TAS1R3 (rs307355; known to be sensitive to the Umami taste) was associated with the consumption of vegetables in the Japanese population [17]. In addition, Calancie and Mikołajczyk-Stecyna et al. reported that TAS2R38 (rs713598, rs1726866, and rs10246939) and gustin (CA6; rs2274333) polymorphisms may affect the frequency of consumption of bitter-tasting foods $[18,19]$.

A recent genome-wide association study (GWAS) revealed many loci associated with adult BMI, and these loci accounted for $2.7 \%$ of BMI variation [20]. Pathways involving synaptic plasticity and glutamate receptor activity were pathways that responded to changes in feeding and fasting and are regulated by obesity-related molecules such as BDNF and MC4R [20]. These findings indicate the importance of gene-environment interactions, such as genetic variations and dietary factors; however, it remains unclear whether a genetic interaction role exists between vegetable intake frequency and BMI or obesity.

Therefore, we conducted a comprehensive search for single nucleotide polymorphisms (SNPs) which interact with the association between various types of vegetables, such as carrot, broccoli, spinach, other green vegetables (green pepper, green beans), pumpkin, and cabbage, and reduced BMI or obesity using a GWAS in Japanese individuals.

\section{Methods}

\subsection{Study Design}

The study participants were customers of the Japanese Direct-to-Consumer genetic testing service, HealthData Lab, provided by Genequest Inc. (Tokyo, Japan) and Yahoo! Japan Corporation (Tokyo, Japan). All participants were over 18 years of age, had answered an online self-reported survey, and had consented to the use of their genotype and questionnaire data for this study. Criteria for inclusion were: (i) aged 18-90 years and (ii) participants of Yahoo HealthData Lab. Criteria for exclusion were those: (i) who had not provided informed consent, (ii) had an incomplete questionnaire or had not provided data, (iii) who were estimated to have non-Japanese ancestry, (iv) who had low call rates per subject, or those with a closely related subject. The final analysis was performed using 12,225 participants. Written informed consent was obtained from all participants. The study purpose was explained to the participants and a further agreement was obtained allowing participants to opt-out. The ethics committee of Niigata University and Genequest Inc. approved the present study (2015-2623 and G2017-0023, 2017-15-1).

\subsection{Frequency of Vegetable Intake Measurement and Definition of BMI}

Frequency of vegetable intake was assessed using an online survey that asked participants "How frequently do you eat carrot, broccoli, spinach, other green vegetables (green pepper and green beans), pumpkin, and cabbage?" The answers included eight categories of intake level: "hardly eat," " 1 to 3 times per month," " 1 to 2 times per week," " 3 to 4 times per week," " 5 to 6 times per a week," "once per day," "twice per day," or " $\geq 3$ times per day." Categories were converted into continuous variables (1 to 8), representing frequency, i.e., "hardly eat" was coded as 1, " 1 to 3 times per month" as 2 , " 1 to 2 times per week" as 3 , "3 to 4 times per week" as 4 , " 5 to 6 times per week" as 5 , "once per day" as 6 , "twice per day" as 7 , and " $\geq 3$ times per day" as 8 . In addition, self-reported information on height and weight was collected from all participants. BMI was calculated by dividing weight $(\mathrm{kg})$ by the square of height $(\mathrm{m})$. Obesity was defined as a BMI $\geq 25.0 \mathrm{~kg} / \mathrm{m}^{2}$, according to the Japan Society for the Study of Obesity [21].

\subsection{DNA Sampling, Genotyping and Quality Control}

Saliva samples were collected using the Oragene DNA (OG-500) Collection Kit (DNA Genotek Inc., Ottawa, ON, Canada), followed by the extraction of genomic DNA accord- 
ing to the manufacturer's instructions. Genotyping was performed using either of two Illumina (San Diego, CA, USA) platforms: the HumanCore-12+ Custom BeadChip or the HumanCore-24+ Custom BeadChip. Since these two platforms were designed to measure almost identical marker sets, we used 285,387 markers genotyped by both platforms. We excluded: (i) those estimated to have non-Japanese ancestry [22,23], (ii) those with low call rates per subject $(<0.95)$, (iii) those with a closely related subject (PI_HAT $>0.1875$ ), (iv) those with inconsistent sex data between questionnaire and genotype, (v) SNP markers with low call rates per SNP $(<0.95)$, (vi) values with significant deviation from the HardyWeinberg equilibrium (exact test $p$ values $<1 \times 10^{-6}$ ), and/or low minor allele frequencies $(<0.01)$.

\subsection{Genome-Wide Association Study (GWAS)}

We conducted a comprehensive search for SNPs that interact with the intake of various vegetables associated with BMI using PLINK (version 1.90b3.42) [24,25].

First, the covariates included age and sex (regression formula: BMI $=\alpha+\beta_{\mathrm{SNP}}{ }^{*} \mathrm{SNP}+$ $\beta_{\text {age }}{ }^{*}$ age $+\beta_{\text {sex }}{ }^{*}$ sex $+\beta_{\text {vegetable intake frequency }}{ }^{*}$ vegetable intake frequency $+\beta_{\text {interaction }}{ }^{*}$ (SNP *vegetable intake frequency)). We then added alcohol intake, smoking, physical activity and the frequency of total vegetable intake as covariates. Manhattan and quantile-quantile plots were created using the R software package qqman [26] (version 0.1.4). For SNPs that reached significance, we created regional association plots using LocusZoom [27] (version 1.3). A $p$ value $<1 \times 10^{-5}$ was considered as suggestive of significance and a $p$ value $<5 \times 10^{-8}$ was regarded as having genome-wide significance.

\section{Results}

A total of 12,225 participants were included in this study (Table 1). The mean BMI was $23.9 \pm 3.4 \mathrm{~kg} / \mathrm{m}^{2}$ and $22.1 \pm 3.8 \mathrm{~kg} / \mathrm{m}^{2}$ for men and women, respectively. The prevalence of obesity was $32.3 \%$ and $17.3 \%$ for men and women, respectively. The mean BMI in individuals with obesity was $27.8 \mathrm{~kg} / \mathrm{m}^{2}$ and $28.5 \mathrm{~kg} / \mathrm{m}^{2}$ for men and women, respectively. High intake frequency of carrot, broccoli, spinach, other green vegetables (green pepper and green beans), and pumpkin was negatively associated with BMI $\left(p=3.7 \times 10^{-8}\right.$, $1.2 \times 10^{-3}, 1.2 \times 10^{-9}, 2.8 \times 10^{-3}, 2.0 \times 10^{-11}$, respectively); no association was observed for cabbage.

\subsection{Interaction between rs4445711 and Frequency of Carrot Intake on BMI}

SNPs with suggestive levels of association $\left(p<1 \times 10^{-5}\right)$ with BMI for each vegetable are shown in Table 2. The GWAS revealed a significant interaction between rs4445711 and frequency of carrot intake on BMI and obesity (Figure 1A, $p=4.5 \times 10^{-8}$; Figure 1B, $p=2.5 \times 10^{-8}$, respectively) adjusted for age and sex. This interaction was slightly attenuated after adjustment for alcohol intake, smoking, physical activity and the frequency of total vegetable intake on BMI $\left(p=2.1 \times 10^{-7}\right)$. Genotype analysis mapped rs4445711 to an intron of the thioredoxin reductase 1 (TXNRD1) gene on human chromosome 12 (Figure 2A), which codes for an antioxidant enzyme regulated by the Nrf2/Keap1 pathway. Figure $2 \mathrm{~B}$ represents the area plot of chromosome 12 showing the relative location of rs4445711. The overall inflation factor $(\lambda)$ for the association analysis was 0.9609 (95\% confidence interval: $0.9510-0.9705)$, suggesting a minimal level of confounding with population stratification (Figure 3). There was no association between each rs4445711 allele (AA, AG, GG) and frequency of carrot intake $(p=0.80)$. In addition, no interactions that are the same as the interaction between frequency of carrot intake and rs4445711 were observed between the frequency of broccoli, spinach, other green vegetables (green pepper and green beans), pumpkin, or cabbage intake and BMI or obesity (Supplemental Table S1). The $\beta$ coefficient for rs4445711 on BMI in the groups which ate carrot 5 or more times per week or less than 5 times per week was -0.438 and 0.128 , respectively. No significant association was observed between rs4445711 variants and underweight $(p=0.49)$. 
Table 1. Characteristics of study participants and frequency of vegetable intake.

\begin{tabular}{|c|c|c|}
\hline Characteristics & Men & Women \\
\hline Number of participants $(n)$ & 6495 & 5730 \\
\hline Age (year) & $51 \pm 13$ & $50 \pm 13$ \\
\hline Body mass index $\left(\mathrm{kg} / \mathrm{m}^{2}\right)$ & $23.9 \pm 3.4$ & $21.1 \pm 3.8$ \\
\hline Obesity $(n, \%)$ & $2097(33)$ & $994(17)$ \\
\hline \multicolumn{3}{|l|}{ Carrot $(n, \%)$} \\
\hline hardly eat & $321(5)$ & $267(5)$ \\
\hline 1 to 3 times per month & $1204(19)$ & $790(14)$ \\
\hline 1 to 2 times per week & $2216(34)$ & $1569(27)$ \\
\hline 3 to 4 times per week & $1257(19)$ & $1172(20)$ \\
\hline 5 to 6 times per week & $500(8)$ & $602(11)$ \\
\hline once per day & $777(12)$ & $858(15)$ \\
\hline twice per day & $183(3)$ & $370(6)$ \\
\hline$\geq 3$ times per day & $37(1)$ & $102(2)$ \\
\hline \multicolumn{3}{|l|}{ Broccoli $(n, \%)$} \\
\hline hardly eat & $1140(18)$ & $761(13)$ \\
\hline 1 to 3 times per month & $2491(38)$ & $2295(40)$ \\
\hline 1 to 2 times per week & $1992(31)$ & $1777(31)$ \\
\hline 3 to 4 times per week & $556(9)$ & $565(10)$ \\
\hline 5 to 6 times per week & $153(2)$ & $160(3)$ \\
\hline once per day & $147(2)$ & $147(3)$ \\
\hline twice per day & $11(0)$ & $18(0)$ \\
\hline$\geq 3$ times per day & $5(0)$ & $7(0)$ \\
\hline \multicolumn{3}{|l|}{ Spinach $(n, \%)$} \\
\hline hardly eat & $321(5)$ & $267(5)$ \\
\hline 1 to 3 times per month & $1204(19)$ & $790(14)$ \\
\hline 1 to 2 times per week & $2216(34)$ & $1569(27)$ \\
\hline 3 to 4 times per week & $1257(19)$ & $1172(20)$ \\
\hline 5 to 6 times per week & $500(8)$ & $602(11)$ \\
\hline once per day & $777(12)$ & $858(35)$ \\
\hline twice per day & $183(3)$ & $370(6)$ \\
\hline$\geq 3$ times per day & $37(1)$ & $102(2)$ \\
\hline \multicolumn{3}{|c|}{$\begin{array}{c}\text { Other green vegetables (green pepper and } \\
\text { green bean) }(n, \%)\end{array}$} \\
\hline hardly eat & $629(10)$ & $368(6)$ \\
\hline 1 to 3 times per month & $2118(33)$ & $1542(27)$ \\
\hline 1 to 2 times per week & $2555(39)$ & $2273(40)$ \\
\hline 3 to 4 times per week & $807(12)$ & $982(17)$ \\
\hline 5 to 6 times per week & $192(3)$ & $275(5)$ \\
\hline once per day & $164(3)$ & $246(4)$ \\
\hline twice per day & $24(0)$ & $34(1)$ \\
\hline$\geq 3$ times per day & $6(0)$ & $10(0)$ \\
\hline \multicolumn{3}{|l|}{ Pumpkin $(n, \%)$} \\
\hline hardly eat & $1405(22)$ & $1020(18)$ \\
\hline 1 to 3 times per month & $2809(43)$ & $2587(45)$ \\
\hline 1 to 2 times per week & $1703(26)$ & $1454(25)$ \\
\hline 3 to 4 times per week & $349(5)$ & $388(7)$ \\
\hline 5 to 6 times per week & $108(2)$ & $124(2)$ \\
\hline once per day & $100(2)$ & $129(2)$ \\
\hline twice per day & $18(0)$ & $22(0)$ \\
\hline$\geq 3$ times per day & $3(0)$ & $6(0)$ \\
\hline \multicolumn{3}{|l|}{ Cabbage $(n, \%)$} \\
\hline hardly eat & $148(2)$ & $118(2)$ \\
\hline 1 to 3 times per month & $1037(16)$ & $976(17)$ \\
\hline 1 to 2 times per week & $2733(42)$ & $2272(40)$ \\
\hline 3 to 4 times per week & $1640(25)$ & $1441(25)$ \\
\hline 5 to 6 times per week & $446(7)$ & $483(8)$ \\
\hline once per day & $419(6)$ & $356(6)$ \\
\hline twice per day & $57(1)$ & $68(1)$ \\
\hline$\geq 3$ times per day & $15(0)$ & $16(0)$ \\
\hline
\end{tabular}


Table 2. SNPs with suggestive levels of association $\left(p<1 \times 10^{-5}\right)$ with body mass index.

\begin{tabular}{|c|c|c|c|c|c|c|c|}
\hline CHR & SNP & Position & EA & NEA & BETA & SE & $p$ \\
\hline \multicolumn{8}{|c|}{ Carrot } \\
\hline 12 & rs 4445711 & 104636601 & $\mathrm{G}$ & A & -0.1682 & 0.03073 & $4.53 \times 10^{-5}$ \\
\hline 17 & rs223154 & 29928083 & $\mathrm{~T}$ & G & -0.1445 & 0.0302 & $1.73 \times 10^{-6}$ \\
\hline 10 & rs4919491 & 95515515 & $\mathrm{G}$ & A & 0.2113 & 0.0467 & $6.09 \times 10^{-6}$ \\
\hline 10 & rs 2483855 & 128933992 & $\mathrm{~A}$ & $\mathrm{G}$ & 0.1761 & 0.03924 & $7.27 \times 10^{-6}$ \\
\hline \multicolumn{8}{|c|}{ Broccoli } \\
\hline 4 & rs993775 & 94731641 & $\mathrm{G}$ & $\mathrm{T}$ & -0.1944 & 0.04095 & $2.07 \times 10^{-6}$ \\
\hline 5 & rs13185886 & 79108476 & $\mathrm{C}$ & $\mathrm{T}$ & 0.216 & 0.04792 & $6.63 \times 10^{-6}$ \\
\hline \multicolumn{8}{|c|}{ Spinach } \\
\hline \multirow{2}{*}{\multicolumn{8}{|c|}{ Other green vegetables (green pepper and green bean) }} \\
\hline & & & & & & & \\
\hline 2 & rs11692441 & 156950640 & G & $\mathrm{T}$ & 0.2319 & 0.05183 & $7.73 \times 10^{-6}$ \\
\hline 2 & rs13429725 & 147292648 & G & A & 0.186 & 0.04198 & $9.44 \times 10^{-6}$ \\
\hline \multicolumn{8}{|c|}{ Pumpkin } \\
\hline 3 & rs902192 & 193111865 & A & G & -0.3404 & 0.07406 & $4.34 \times 10^{-6}$ \\
\hline 16 & rs9932117 & 54906895 & $\mathrm{C}$ & A & 0.2347 & 0.05141 & $5.01 \times 10^{-6}$ \\
\hline \multicolumn{8}{|c|}{ Cabbage } \\
\hline 3 & rs12490455 & 176910577 & $\mathrm{~T}$ & $\mathrm{C}$ & -0.2017 & 0.04464 & $6.32 \times 10^{-6}$ \\
\hline
\end{tabular}

CHR—chromosome; SNPs—single nucleotide polymorphisms; EA—effect allele; NEA—non-effect allele; BETA—beta-interaction; SEstandard error; $p-p$-value.

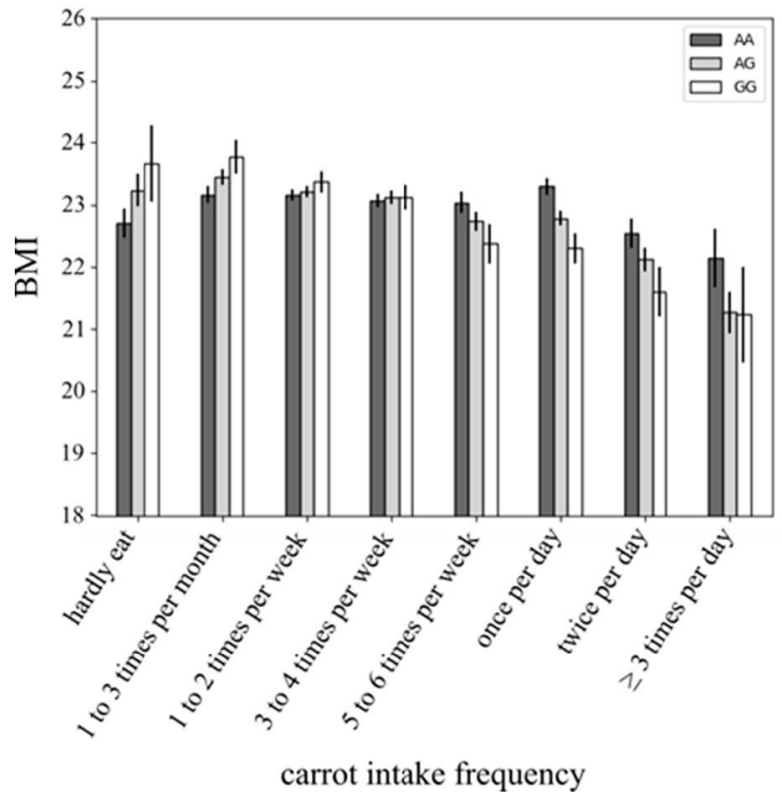

(A)

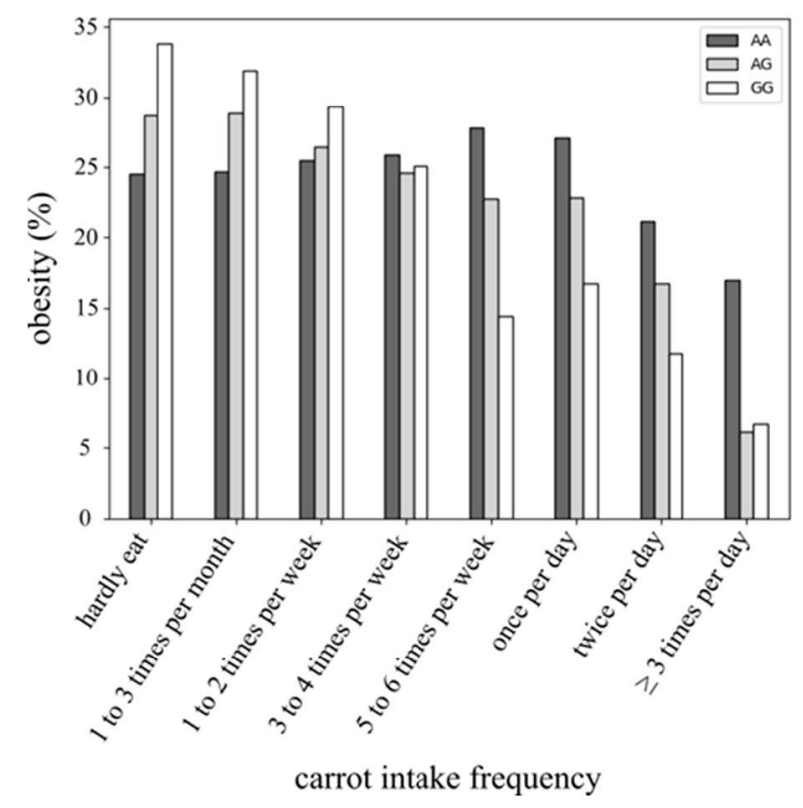

(B)

Figure 1. Interaction between rs4445711 and frequency of carrot intake on body mass index (BMI) (A) and obesity (B) in both men and women. 


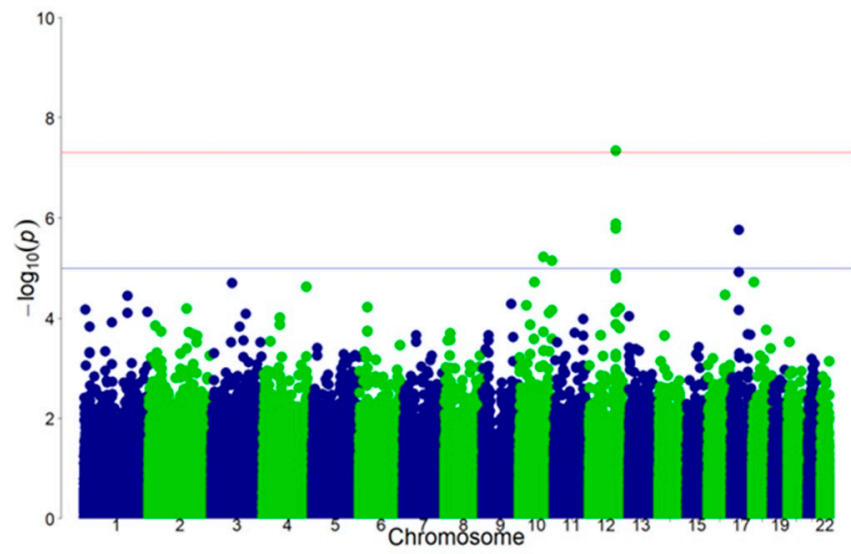

(A)

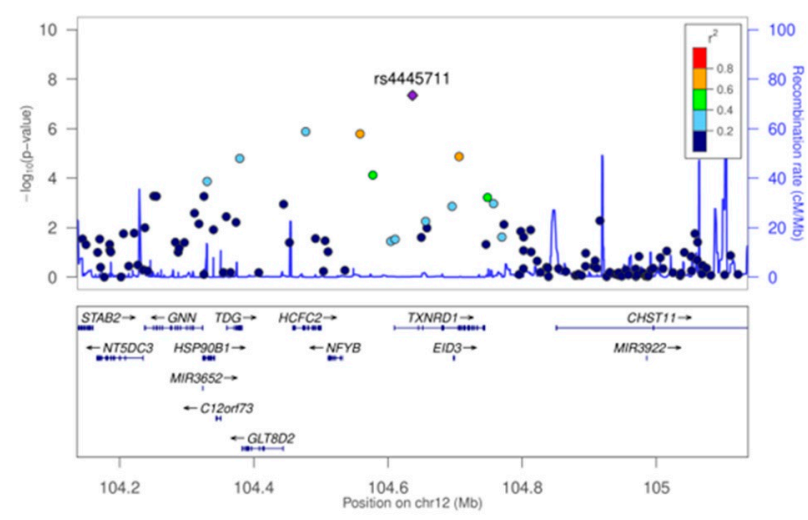

(B)

Figure 2. (A) Manhattan plot analysis. The $x$-axis represents chromosomal positions and the $y$-axis represents $-\log _{10} p$ values. The red and blue horizontal lines indicate the genome-wide significance $\left(p=5.0 \times 10^{-8}\right)$ and suggestive significance $\left(p=5.0 \times 10^{-5}\right)$ levels, respectively. (B) Area plot of chromosome 12, showing the relative location of rs4445711.

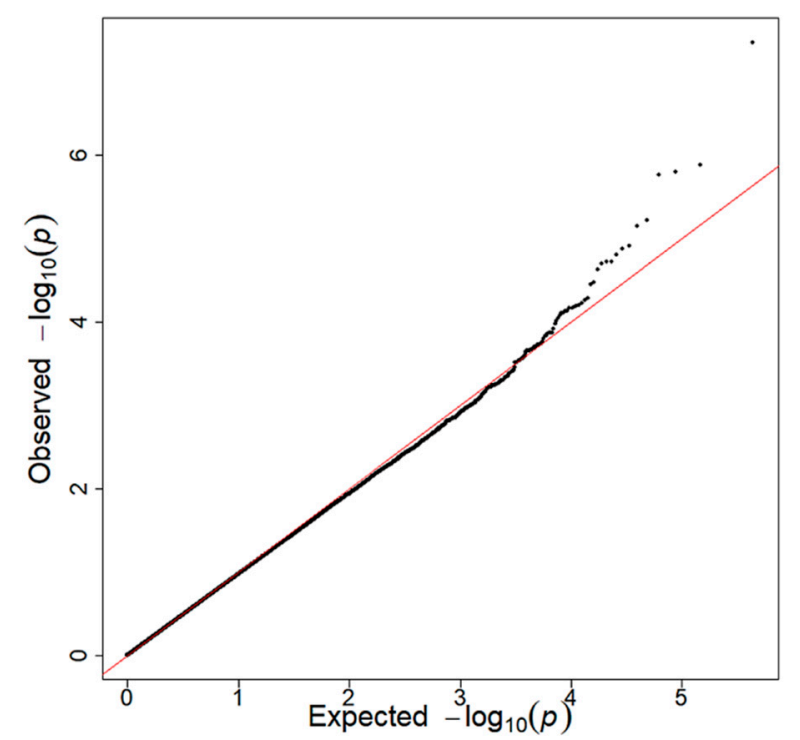

Figure 3. A quantile-quantile plot for the genome-wide meta-analysis showing the $p$ value distribution. The $x$-axis represents theoretical $-\log _{10} p$ values, and the $y$-axis represents observed $-\log _{10} p$ values. The red line indicates $y=x$.

\subsection{Subgroup Analysis}

Figures 4 and 5 show the association between each rs4445711 allele and frequency of carrot intake in men and women and each age category, respectively. The interaction between rs4445711 and BMI was consistent between men and women ( $p$ values for interactions in male and female groups were $5.9 \times 10^{-6}$ and $7.6 \times 10^{-4}$, respectively). However, across the age groups, the $p$ values for interactions in the younger ( $\leq 39$ years), middle aged (40-59 years), and older adult ( $\geq 60$ years) groups were $0.0111,6.0 \times 10^{-6}$, and 0.192 , respectively; no significant interaction was observed in the older adult group. 


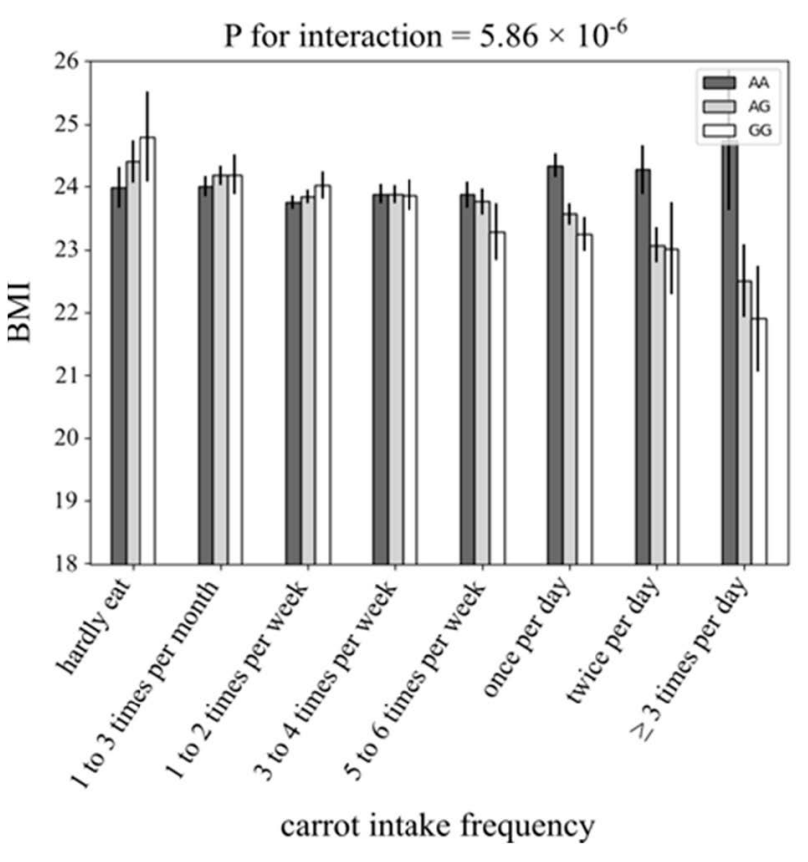

(A)

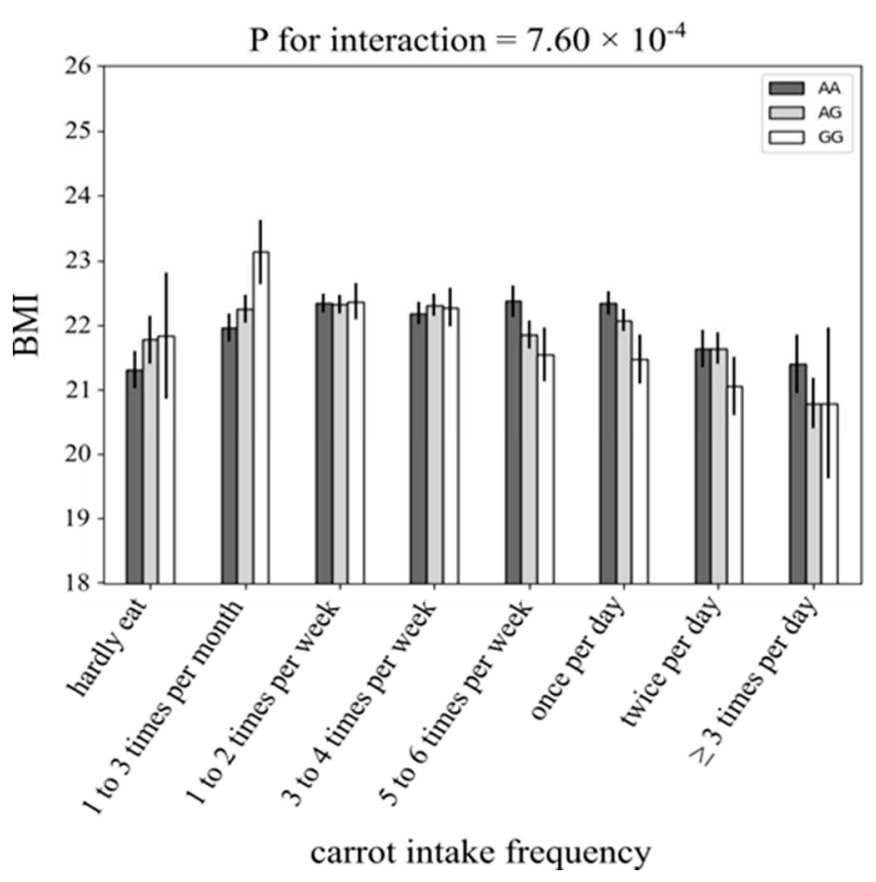

(B)

Figure 4. The association between each rs4445711 allele and frequency of carrot intake: subgroup analysis stratified by sex. The $y$-axis represents body mass index according to the genotype of the lead variant at rs4445711-i.e., GG, AG, or AA-and the $x$-axis shows the 8 categories of carrot intake frequency, (A) male, and (B) female.

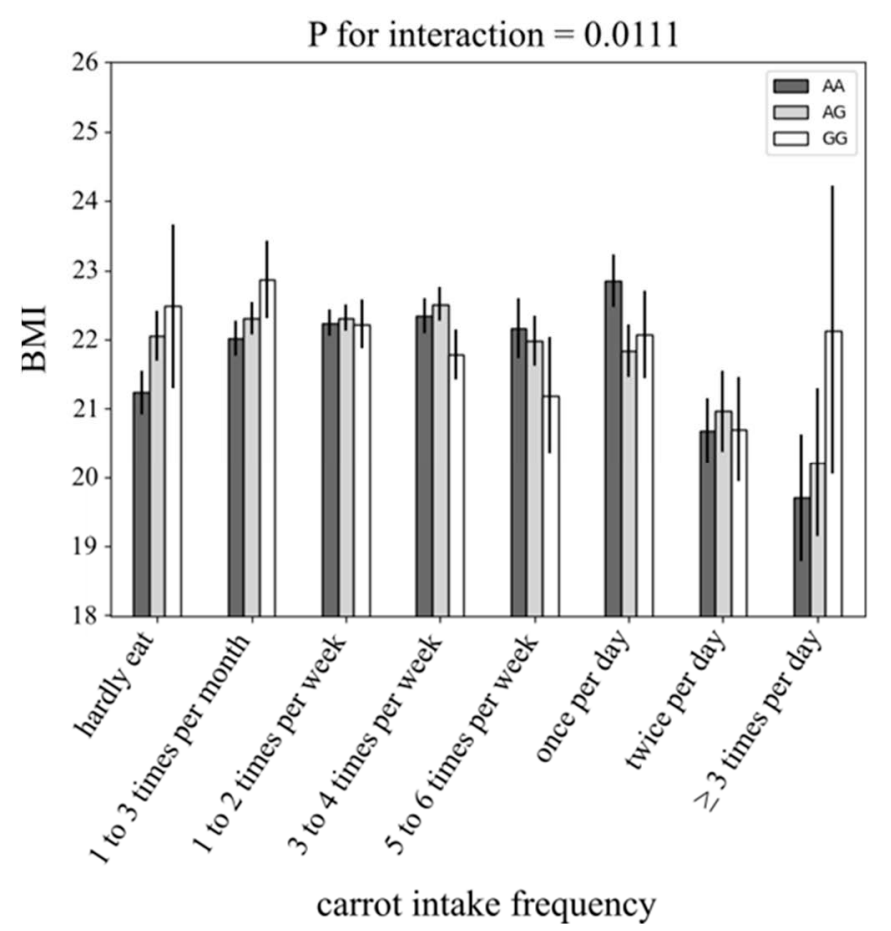

(A)

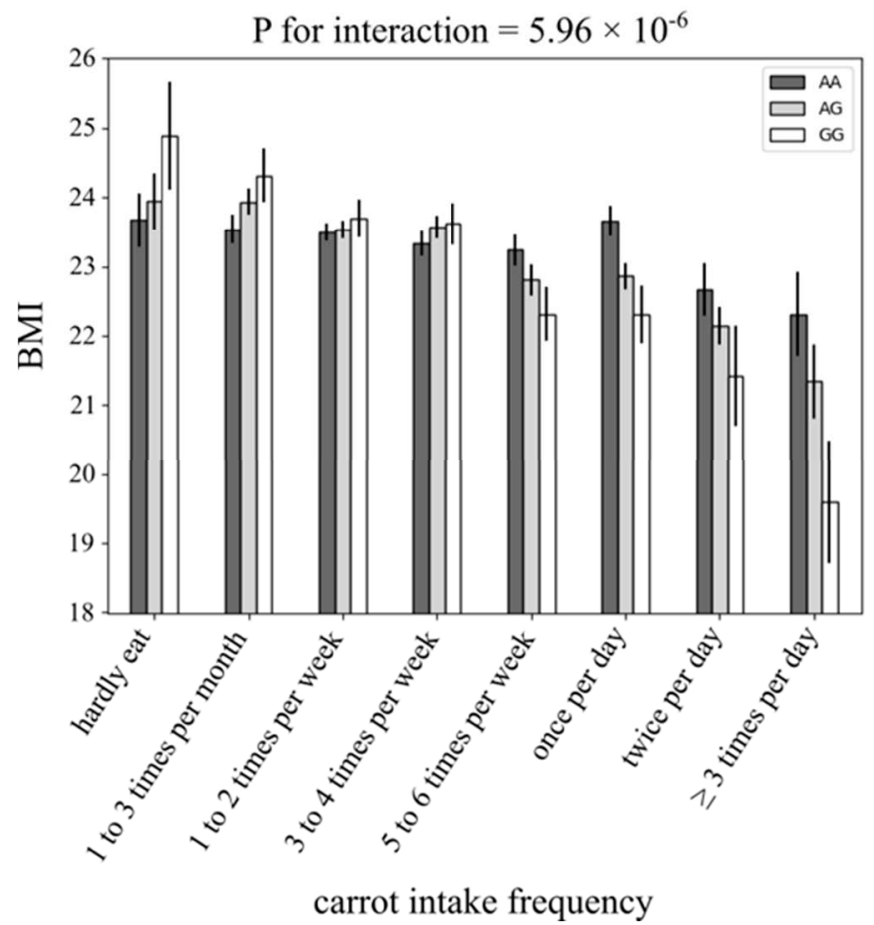

(B)

Figure 5. Cont. 


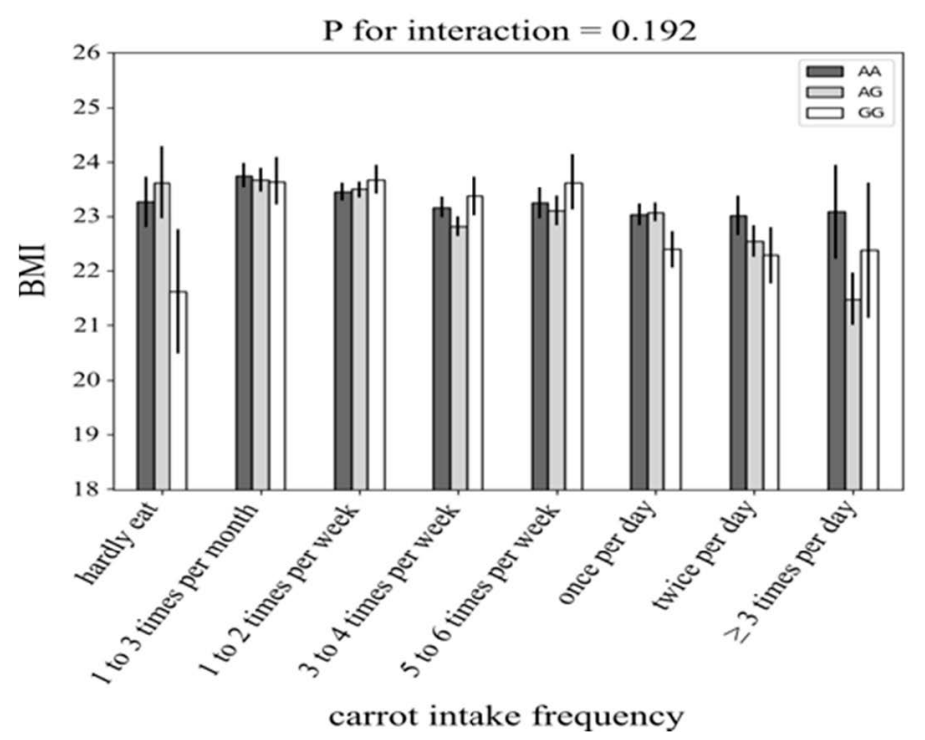

(C)

Figure 5. The association between each rs4445711 allele and frequency of carrot intake: subgroup analysis stratified by age. The $y$-axis represents body mass index according to the genotype of the lead variant at rs4445711-i.e., GG, AG, or AA-and the $x$-axis shows the 8 categories of carrot intake frequency, (A) younger ( $\leq 39$ years), (B) middle aged (40-59 years), and (C) older adult ( $\geq 60$ years).

\section{Discussion}

This is the first report of a comprehensive search for SNPs which associate with the interaction between vegetable intake and BMI or obesity using a GWAS of the Japanese population.

We showed interactions between frequency of carrot intake and the rs4445711 variant on BMI and obesity. Our data indicated that the G allele of rs4445711 was associated with lower BMI or obesity in individuals with higher frequency of carrot intake.

There have been no consistent reports on an association between vegetable consumption and subsequent decrease in BMI. Wall et al. reported that children who ate vegetables three or more times per week had a lower BMI compared to children who never or occasionally reported eating vegetables [13]. However, no association was observed between vegetable intake in children and the risk of becoming overweight/obese in Western countries $[14,15]$. In addition, Charlton et al. suggested that improving adherence to dietary targets for fruits and vegetables may be a dietary strategy to overcome overweight among men but not among women [12]. The results indicate the importance of gene-environment interactions, such as genetic variations and frequency of specific vegetable intake. As far as we know, this is the first study to determine the role of interactions between specific genetic factors and the frequency of specific vegetable intake on BMI or obesity. The interaction between frequency of carrot intake and BMI may be dependent on rs4445711; suggesting that carrot intake may contribute to BMI values through rs4445711.

Carrots are rich in carotenoid antioxidants, such as $\beta$-carotene, $\alpha$-carotene and $\beta$ cryptoxanthin. Epidemiological studies have shown that a high content of $\beta$-carotene in the blood correlates with a low incidence of type 2 diabetes, cancers and mortality [28-32]. Serum $\beta$-carotene has also been inversely associated with systemic markers of inflammation and insulin resistance $[33,34]$. A small-sized cross-sectional study showed that higher intakes of cryptoxanthin was related to low BMI in middle-aged Japanese women [35]. A longitudinal study showed that changes in serum $\beta$-cryptoxanthin levels were inversely correlated with changes in BMI in Western countries [36] and Iwata et al. reported that a $\beta$-cryptoxanthin-containing beverages produced a greater decrease in BMI and visceral fat area compared with a placebo beverage in pre-obese Japanese men [37]. These results 
indicate that increased carrot intake may lead to an increase in nutrients which interact with the rs4445711 G-allele. As a result, increased frequency of carrot intake may enhance the reduction in insulin resistance. Future studies are necessary to clarify the effects of serum levels of $\alpha$-carotene, $\beta$-carotene, $\beta$-cryptoxanthin and systemic markers of inflammation and insulin resistance on the association between the rs4445711 G-allele and BMI.

The SNP rs4445711 is located in an intron of thioredoxin reductase 1 (TXNRD1) [38], an antioxidant enzyme regulated by the Nrf2/Keap1 pathway. Although rs4445711 has not been reported in the GWAS catalog, other SNPs on TXNRD1 have potential associations with free IGF-1 (rs11112046, $p=3.34 \times 10^{-6}$ ) [39-41]. In addition, TXNRD1 levels in adipose tissue correlated with BMI [42]. A previous study showed that rs4445711 associated with the expression of E1A-like inhibitor of differentiation 3 (EID3) and thymine DNA glycosylase (TDG) in subcutaneous fat using eQTL analysis $\left(p=9.4 \times 10^{-19}, p=2.4 \times 10^{-6}\right)$ [43] The expression of EID3 was varied in other tissues [44]. Although further research is needed to understand the association between these results and our findings, our results may provide a clue to the mechanism of individual differences in BMI with regard to vegetable intake.

Our study has several limitations. First, we have no data on total carrot intake and carrot cultivars. Second, BMI data were self-reported via the internet, which may have introduced measurement error; however, the accuracy of internet-based BMI is reported to be high [45]. It is important to note that the definition of obesity differs between Japan and Western countries. Third, people who eat more carrots may have other healthy lifestyle behaviors; however, the results did not change even after adjusting for the effects of other vegetable intakes and exercise habits. Forth, although we have made efforts to adjust for factors that might affect BMI, residual confounding factors may exist, such as total calories, macro-nutrients, and dietary fiber intake. Fifth, we did not collect serum carotenoid concentration.

In conclusion, the frequency of carrot consumption has been implicated in reducing the BMI through the intermediary of rs4445711. This novel genetic association may provide new clues to clarify the association between vegetable intake and BMI.

Supplementary Materials: The following are available online at https:/ / www.mdpi.com/article/10 $.3390 /$ nu13103478/s1, Table S1: Interactions between rs4445711 and frequency of various types of vegetable intake on body mass index.

Author Contributions: H.S. (Hirohito Sone) had full access to all of the data in the study and takes responsibility for the integrity of the data and the accuracy of the data analysis. Study members that contributed significantly to this work are as follows: Study concept and design: K.F., S.N. and K.S.; Acquisition of data: K.F., S.N. and K.S.; Analysis and interpretation of data: K.F., S.N., C.H., K.S. and S.K.; Drafting of the manuscript: K.F., S.N., Y.T., K.C., H.I., Y.N. and T.M.; Critical revision of the manuscript for important intellectual content: K.F., S.N., K.S., S.K. and H.S. (Hitoshi Shimano); Statistical analysis: S.N.; Study supervision: S.K. and H.S. (Hirohito Sone). All authors have read and agreed to the published version of the manuscript.

Funding: This work is supported in part by the Japan Society for the Promotion of Science (19H04028).

Institutional Review Board Statement: The study was conducted according to the guidelines of the Declaration of Helsinki, and approved by the Ethics Committee of the Niigata University and Genequest Inc. (protocol code 2015-2623 and G2017-0023, 2017-15-1).

Informed Consent Statement: Informed consent was obtained from all subjects involved in the study.

Data Availability Statement: All data analyzed during this study are included in this paper and its additional files. Other data are available from the author upon reasonable request.

Acknowledgments: The authors would like to thank Mami Haga, Niigata University Faculty of Medicine, for excellent secretarial assistance.

Conflicts of Interest: S.N. is an employee of Genequest Inc.; K.S. is a board member of Genequest Inc. K.F., C.H., S.K. and H.S. declare no potential conflict of interest. 
Ethical Approval: The ethics committee of the Niigata University and Genequest Inc. approved the present study (2015-2623 and G2017-0023, 2017-15-1).

Informed Consent: Informed consent was acquired and signed by each patient enrolled in the study.

$\begin{array}{ll}\text { Abbreviations } \\ \text { BMI } & \text { body mass index } \\ \text { EID } & \text { E1A-like inhibitor of differentiation } \\ \text { GWAS } & \text { genome wide association study } \\ \text { SNPs } & \text { single nucleotide polymorphisms } \\ \text { TXNRD } & \text { thioredoxin reductase }\end{array}$

\section{References}

1. Wang, X.; Ouyang, Y.; Liu, J.; Zhu, M.; Zhao, G.; Bao, W.; Hu, F.B. Fruit and vegetable consumption and mortality from all causes, cardiovascular disease, and cancer: Systematic review and dose-response meta-analysis of prospective cohort studies. BMJ 2014, 349, g4490. [CrossRef] [PubMed]

2. Boeing, H.; Bechthold, A.; Bub, A.; Ellinger, S.; Haller, D.; Kroke, A.; Leschik-Bonnet, E.; Müller, M.J.; Oberritter, H.; Schulze, M.; et al. Critical review: Vegetables and fruit in the prevention of chronic diseases. Eur. J. Nutr. 2012, 51, 637-663. [CrossRef] [PubMed]

3. Blüher, M. Obesity: Global epidemiology and pathogenesis. Nat. Rev. Endocrinol. 2019, 15, 288-298. [CrossRef] [PubMed]

4. Hruby, A.; Hu, F.B. The Epidemiology of Obesity: A Big Picture. Pharmacoeconomics 2015, 33, 673-689. [CrossRef] [PubMed]

5. WHO. Obesity and Overweight. Available online: https://www.who.int/news-room/fact-sheets/detail/obesity-andoverweight (accessed on 9 June 2021).

6. Katz, D.A.; McHorney, C.A.; Atkinson, R.L. Impact of obesity on health-related quality of life in patients with chronic illness. J. Gen. Intern. Med. 2000, 15, 789-796. [CrossRef]

7. Taylor, V.H.; Forhan, M.; Vigod, S.; McIntyre, R.S.; Morrison, K. The impact of obesity on quality of life. Best Pract. Res. Clin. Endocrinol. Metab. 2013, 27, 139-146. [CrossRef] [PubMed]

8. Schlesinger, S.; Neuenschwander, M.; Schwedhelm, C.; Hoffmann, G.; Bechthold, A.; Boeing, H.; Schwingshackl, L. Food Groups and Risk of Overweight, Obesity, and Weight Gain: A Systematic Review and Dose-Response Meta-Analysis of Prospective Studies. Adv. Nutr. 2019, 10, 205-218. [CrossRef]

9. Nour, M.; Lutze, S.A.; Grech, A.; Allman-Farinelli, M. The Relationship between Vegetable Intake and Weight Outcomes: A Systematic Review of Cohort Studies. Nutrients 2018, 10, 1626. [CrossRef]

10. Mozaffarian, D.; Hao, T.; Rimm, E.B.; Willett, W.C.; Hu, F.B. Changes in Diet and Lifestyle and Long-Term Weight Gain in Women and Men. N. Engl. J. Med. 2011, 364, 2392-2404. [CrossRef]

11. Bertoia, M.L.; Mukamal, K.J.; Cahill, L.E.; Hou, T.; Ludwig, D.S.; Mozaffarian, D.; Willett, W.C.; Hu, F.B.; Rimm, E.B. Changes in Intake of Fruits and Vegetables and Weight Change in United States Men and Women Followed for Up to 24 Years: Analysis from Three Prospective Cohort Studies. PLoS Med. 2015, 12, e1001878. [CrossRef]

12. Charlton, K.; Kowal, P.; Soriano, M.M.; Williams, S.; Banks, E.; Vo, K.; Byles, J. Fruit and Vegetable Intake and Body Mass Index in a Large Sample of Middle-Aged Australian Men and Women. Nutrients 2014, 6, 2305-2319. [CrossRef] [PubMed]

13. Wall, C.R.; Stewart, A.W.; Hancox, R.J.; Murphy, R.; Braithwaite, I.; Beasley, R.; Mitchell, E.A.; ISAAC Phase Three Study Group. Association between Frequency of Consumption of Fruit, Vegetables, Nuts and Pulses and BMI: Analyses of the International Study of Asthma and Allergies in Childhood (ISAAC). Nutrients 2018, 10, 316. [CrossRef] [PubMed]

14. Field, A.E.; Gillman, M.W.; Rosner, B.; Rockett, H.R.; Colditz, G. Association between fruit and vegetable intake and change in body mass index among a large sample of children and adolescents in the United States. Int. J. Obes. 2003, 27, 821-826. [CrossRef] [PubMed]

15. Rautiainen, S.; Wang, L.; Lee, I.M.; Manson, J.E.; Buring, J.E.; Sesso, H.D. Higher Intake of Fruit, but Not Vegetables or Fiber, at Baseline Is Associated with Lower Risk of Becoming Overweight or Obese in Middle-Aged and Older Women of Normal BMI at Baseline. J. Nutr. 2015, 145, 960-968. [CrossRef]

16. Yuan, S.; Yu, H.J.; Liu, M.W.; Huang, Y.; Yang, X.H.; Tang, B.W.; Song, Y.; Cao, Z.K.; Wu, H.J.; He, Q.Q.; et al. The association of fruit and vegetable consumption with changes in weight and body mass index in Chinese adults: A cohort study. Public Health 2018, 157, 121-126. [CrossRef]

17. Matoba, N.; Akiyama, M.; Ishigaki, K.; Kanai, M.; Takahashi, A.; Momozawa, Y.; Ikegawa, S.; Ikeda, M.; Iwata, N.; Hirata, M.; et al. GWAS of 165,084 Japanese individuals identified nine loci associated with dietary habits. Nat. Hum. Behav. 2020, 4, 308-316. [CrossRef]

18. Calancie, L.; Keyserling, T.C.; Taillie, L.S.; Robasky, K.; Patterson, C.; Ammerman, A.S.; Schisler, J.C. TAS2R38 Predisposition to Bitter Taste Associated with Differential Changes in Vegetable Intake in Response to a Community-Based Dietary Intervention. G3 Genes Genomes Genet. 2018, 8, 2107-2119. [CrossRef] 
19. Mikołajczyk-Stecyna, J.; Malinowska, A.; Chmurzynska, A. TAS2R38 and CA6 genetic polymorphisms, frequency of bitter food intake, and blood biomarkers among elderly woman. Appetite 2017, 116, 57-64. [CrossRef]

20. Locke, A.E.; Kahali, B.; Berndt, S.I.; Justice, A.E.; Pers, T.H.; Day, F.R.; Powell, C.; Vedantam, S.; Buchkovich, M.L.; Yang, J.; et al. Genetic studies of body mass index yield new insights for obesity biology. Nature 2015, 518, 197-206. [CrossRef]

21. Examination Committee of Criteria for 'Obesity Disease' in Japan. New criteria for 'obesity disease' in Japan. Circ. J. 2002, 66, 987-992. [CrossRef]

22. Yamaguchi-Kabata, Y.; Nakazono, K.; Takahashi, A.; Saito, S.; Hosono, N.; Kubo, M.; Nakamura, Y.; Kamatani, N. Japanese Population Structure, Based on SNP Genotypes from 7003 Individuals Compared to Other Ethnic Groups: Effects on PopulationBased Association Studies. Am. J. Hum. Genet. 2008, 83, 445-456. [CrossRef]

23. Price, A.L.; Patterson, N.J.; Plenge, R.M.; Weinblatt, M.E.; Shadick, N.A.; Reich, D. Principal components analysis corrects for stratification in genome-wide association studies. Nat. Genet. 2006, 38, 904-909. [CrossRef]

24. Purcell, S.; Neale, B.; Todd-Brown, K.; Thomas, L.; Ferreira, M.A.R.; Bender, D.; Maller, J.; Sklar, P.; de Bakker, P.I.W.D.; Daly, M.J.; et al. PLINK: A Tool Set for Whole-Genome Association and Population-Based Linkage Analyses. Am. J. Hum. Genet. 2007, 81, 559-575. [CrossRef]

25. Chang, C.C.; Chow, C.C.; Tellier, L.C.A.M.; Vattikuti, S.; Purcell, S.M.; Lee, J.J. Second-generation PLINK: Rising to the challenge of larger and richer datasets. GigaScience 2015, 4, 7. [CrossRef] [PubMed]

26. Turner, S.D. qqman: An R package for visualizing GWAS results using QQ and manhattan plots. BioRxiv 2014, 1, 005165.

27. Pruim, R.J.; Welch, R.P.; Sanna, S.; Teslovich, T.M.; Chines, P.S.; Gliedt, T.P.; Boehnke, M.; Abecasis, G.; Willer, C.J. LocusZoom: Regional visualization of genome-wide association scan results. Bioinformatics 2010, 26, 2336-2337. [CrossRef] [PubMed]

28. Ford, E.S.; Will, J.C.; Bowman, B.A.; Narayan, K.M.V. Diabetes Mellitus and Serum Carotenoids: Findings from the Third National Health and Nutrition Examination Survey. Am. J. Epidemiol. 1999, 149, 168-176. [CrossRef] [PubMed]

29. Coyne, T.; Ibiebele, T.I.; Baade, P.D.; Dobson, A.; McClintock, C.; Dunn, S.; Leonard, D.; Shaw, J. Diabetes mellitus and serum carotenoids: Findings of a population-based study in Queensland, Australia. Am. J. Clin. Nutr. 2005, 82, 685-693. [CrossRef]

30. Zheng, J.S.; Sharp, S.J.; Imamura, F.; Chowdhury, R.; Gundersen, T.E.; Steur, M.; Sluijs, I.; van der Schouw, Y.T.; Agudo, A.; Aune, D.; et al. Association of plasma biomarkers of fruit and vegetable intake with incident type 2 diabetes: EPIC-InterAct case-cohort study in eight European countries. BMJ 2020, 370, m2194. [CrossRef] [PubMed]

31. Albanes, D. Beta-carotene and lung cancer: A case study. Am. J. Clin. Nutr. 1999, 69, 1345S-1350S. [CrossRef] [PubMed]

32. Huang, J.; Weinstein, S.J.; Yu, K.; Männistö, S.; Albanes, D. Serum Beta Carotene and Overall and Cause-Specific Mortality. Circ. Res. 2018, 123, 1339-1349. [CrossRef] [PubMed]

33. Erlinger, T.P.; Guallar, E.; Miller, E.R., 3rd; Stolzenberg-Solomon, R.; Appel, L.J. Relationship between systemic markers of inflammation and serum beta-carotene levels. Arch. Intern. Med. 2001, 161, 1903-1908. [CrossRef]

34. Higuchi, K.; Saito, I.; Maruyama, K.; Eguchi, E.; Mori, H.; Tanno, S.; Sakurai, S.; Kishida, T.; Nishida, W.; Osawa, H.; et al. Associations of serum $\beta$-carotene and retinol concentrations with insulin resistance: The Toon Health Study. Nutrition 2015, 31, 975-980. [CrossRef] [PubMed]

35. Hirose, A.; Terauchi, M.; Hirano, M.; Akiyoshi, M.; Owa, Y.; Kato, K.; Kubota, T. Higher intake of cryptoxanthin is related to low body mass index and body fat in Japanese middle-aged women. Maturitas 2016, 96, 89-94. [CrossRef] [PubMed]

36. Andersen, L.F.; Jacobs, D.R.; Gross, M.D.; Schreiner, P.J.; Williams, O.D.; Lee, D.-H. Longitudinal associations between body mass index and serum carotenoids: The CARDIA study. Br. J. Nutr. 2006, 95, 358-365. [CrossRef] [PubMed]

37. Iwata, A.; Matsubara, S.; Miyazaki, K. Beneficial effects of a beta-cryptoxanthin-containing beverage on body mass index and visceral fat in pre-obese men: Double-blind, placebo-controlled parallel trials. J. Funct. Foods 2018, 41, 250-257. [CrossRef]

38. Crosley, L.; Méplan, C.; Nicol, F.; Rundlöf, A.; Arnér, E.; Hesketh, J.; Arthur, J. Differential regulation of expression of cytosolic and mitochondrial thioredoxin reductase in rat liver and kidney. Arch. Biochem. Biophys. 2007, 459, 178-188. [CrossRef]

39. Buniello, A.; MacArthur, J.A.L.; Cerezo, M.; Harris, L.W.; Hayhurst, J.; Malangone, C.; McMahon, A.; Morales, J.; Mountjoy, E.; Sollis, E.; et al. The NHGRI-EBI GWAS Catalog of published genome-wide association studies, targeted arrays and summary statistics 2019. Nucleic Acids Res. 2019, 47, D1005-D1012. [CrossRef]

40. Comuzzie, A.G.; Cole, S.A.; Laston, S.L.; Voruganti, V.S.; Haack, K.; Gibbs, R.A.; Butte, N.F. Novel genetic loci identified for the pathophysiology of childhood obesity in the Hispanic population. PLoS ONE 2012, 7, e51954. [CrossRef]

41. Rundlöf, A.-K.; Arnér, E. Regulation of the Mammalian Selenoprotein Thioredoxin Reductase 1 in Relation to Cellular Phenotype, Growth, and Signaling Events. Antioxid. Redox Signal. 2004, 6, 41-52. [CrossRef]

42. Peng, X.; Giménez-Cassina, A.; Petrus, P.; Conrad, M.; Rydén, M.; Arnér, E.S. Thioredoxin reductase 1 suppresses adipocyte differentiation and insulin responsiveness. Sci. Rep. 2016, 6, 28080. [CrossRef] [PubMed]

43. GTEx Portal. Available online: https://gtexportal.org/home/faq\#citePortal (accessed on 1 August 2021).

44. Lonsdale, J.; Thomas, J.; Salvatore, M.; Phillips, R.; Lo, E.; Shad, S.; Hasz, R.; Walters, G.; Garcia, F.; Young, N.; et al. The Genotype-Tissue Expression (GTEx) project. Nat. Genet. 2013, 45, 580-585. [CrossRef] [PubMed]

45. Pursey, K.; Burrows, T.L.; Stanwell, P.; Collins, C.E. How accurate is web-based self-reported height, weight, and body mass index in young adults? J. Med. Internet Res. 2014, 16, e4. [CrossRef] [PubMed] 